\title{
A survey on impact of interval and combined training on breast stroke swimming
}

\author{
Allahyar Arabmomeni ${ }^{\mathbf{a}^{*}}$, Ghasem poorgolizadeh ${ }^{\mathrm{b}}$, Mohammad Reza Iravani $^{\mathrm{c}}$ and Faezeh Taghipour $^{\mathrm{d}}$
}

${ }^{a}$ Department of Human Science of Islamic Azad University Khomeinishahr Branch, Isfahan, Iran

${ }^{b}$ Department of Human Science of Islamic Azad University Najafabad Branch, Isfahan, Iran

${ }^{c}$ Department of Social Work, Islamic Azad University, Khomeinishahr Branch, Daneshjou Blvd, Isfahan, Iran

${ }^{d}$ Assistant Professor, Department of Cultural Management Khorasgan (Isfahan) Branch, Islamic Azad University, Isfahan, Iran

\section{H R O N I C L E}

Article history:

Received June 2, 2012

Received in revised format

28 October 2012

Accepted 30 October 2012

Available online

November 42012

Keywords:

Swimming

Interval swimming

Combined swimming

\begin{abstract}
A B S T R A C T
Swimming is of the most important sports in the world and most countries try to find the most qualified people for participating in world's different championships. Training athletic people in swimming sport is more important in this area of sports compared with other sports. In this paper, we perform an empirical investigation to find the effects of various swimming sports on swimmers. The focus of this study is to compare the performance of two methods before and after two methods of interval and combined breast stroke swimming. The population of this survey includes all teenagers aged 13 and 14 who had, at least, one year of swimming experience. The sampling includes 30 people who were randomly selected and they were divided into two groups of 15 people. One group participated in interval training for three sessions per week and in an eight-week period. The second group took part in combined training for three sessions per week and in an eight-week period. At the end of training program, we have compared the results using t-student. Combined swimming includes different types of exercises. The results show that although there is a meaningful difference before and after two types of training programs but there is no different between the performances of these two tests.
\end{abstract}

C 2013 Growing Science Ltd. All rights reserved.

\section{Introduction}

Swimming is of the most important sports in the world and most countries try to find the most qualified people for participating in world's different championships. Swimming is one of the most popular sports among people in any age and it can help improve people's physical capabilities. Swimming pool must maintain good health condition to help people swim well. Swimming is considered as one of the most "perfect" sports because of its low injury rate and the advantages of swimming, regardless of one's age or capabilities. While injuries can occur in the sport, they are unlikely to be associated with the very highest levels of competition. Water is a primary source of resistance, and helps us through buoyancy and needs more work to move through than air. However, 
the stress of the movement is moved from the weight-bearing joints to the actual muscles, which means any movements done in the water can be both aerobic and anaerobic.

According Kaydos-Daniels et al. (2008), high chloramine levels can cause illness in individuals who are either in or near the pool. This outbreak underscores the requirement for regular pool maintenance, improved air quality, education and certification for all operators of public and semipublic pools, and education about healthy swimming practices. Salmon (2001) studied the effects of physical exercise on anxiety, depression, and sensitivity to stress. He concluded that exercise training could offer clinical psychologists a tool for nonspecific therapeutic social and psychological processes.

Government can also play an important role on facilitating sport among societies. Barros (2003) explained that in all sports, organizational training can forms a necessary component of the activities of sport federations, associations and clubs to help people learn more skills as well as to improve competitiveness. It can also offer a specific psychological medication, which may be particularly efficient for patients. The other important factor is parental involvement in helping children's swimming capabilities.

Wuerth et al. (2004), for instance, investigated the pattern of involvement of parents in youth sport across career phases and career transitions, and determined this pattern from the perspective of athletes and both of their parents. Their results added confidence to the cross-cultural validity of the PISQ. They corroborated the assumption that both parents play an important role in an athlete's career development. Musacchio and Forcier (2008) explained that most risk-taking attitudes developed during adolescence into later life, influencing adult morbidity and mortality. They discussed that approximately 2 million adolescents die per year from mostly preventable and treatable causes making them a critical population for public health intervention. They explained that many of these incidents could be prevented through swimming exercises.

Schoefer et al. (2008) explained that swimming pool attendance and exposure to chlorination byproducts demonstrated adverse health impacts on children. They investigated whether early swimming pool attendance, especially baby swimming, was associated with higher rates of early infections and to the development of allergic diseases. The results showed that, in terms of infections, baby swimming could not be as harmless as people may think about.

Combined strength and endurance training in competitive swimmers has become an interesting research among researchers. Aspenes et al. (2009) performed a survey in combined strength and endurance training the impact of a combined intervention, which included maximal strength training and high-intensity interval training on swimming performance including 50, 100 and 400 meters time trial taken before the intervention and swimming related factors including swimming force, oxygen consumption and velocity. The investigation contained two groups where the first group included a control group that swam with their club team and recorded their workouts and an intervention group that intervened with eleven-week strength and high endurance training schedule in combination with their ordinary swim training. They reported that the eleven-week intervention group had statistically significant improvements in their land force, swimming force and 400 meter time and the 400 meter time was 4 seconds faster in the intervention group than the control group. The intervention group also demonstrated twice the force in the water as the control group.

Swimming plays an important role on reducing human deceases. Schultz et al. (2012), for instance, studied the impact of swimming training in reducing the nonalcoholic fatty liver disease (NAFLD) and related comorbidities, including the hepatic expression of fatty acid synthesis and peroxisome proliferator receptor activity-alpha. The results of their survey confirmed the notion that swimming exercise could be considered as an effective nonpharmacologic therapy in the treatment of NAFLD, obesity and insulin resistance. Another advantage of swimming is to reduced unwanted stress. Coppes 
et al. (1995) explained that adrenaline could be taken up by sympathetic nerve endings through cocaine-sensitive uptake carriers and was released from these nerves during swimming exercise.

Liu et al. (2010) investigated the impact of swimming exercise in combined stress and whether its biological mechanism was associated with the HSP70 and iNOS in hippocampus and prefrontal cortex. They reported that swimming exercise could not only help behavior changes and protect the function of HPA axis stable in CUMS animals exposed to novel acute stress, but also it could increase the HSP70 expression and decrease the iNOS expression in hippocampus and prefrontal cortex. In other words, swimming exercise was beneficial in combined stress by up-regulating HSP70 level and down-regulating iNOS level in brain. Garcia-Marquez and Armario (1987) investigated chronic stress depresses exploratory activity and behavioral performance in the forced swimming test without altering ACTH response to a novel acute stressor.

Many clinical studies have demonstrated that circadian rhythmic abnormalities are strongly related to major depression. Meanwhile a significance number of researches have explained that physical exercise could reduce the stress impairment and improve one's mood, cognition and self-concept. Zhao et al. (2012) explained the impacts of chronic unpredictable mild stress (CUMS) on rodent attitude and the circadian rhythm of hormone and peptide levels in the plasma. They reported that swimming exercise could not reduce the depressive-like behaviors and the blunted circadian rhythmic expression of blood hormone and peptide. It also did not show any impact on the depressive-like behaviors and alterations of blood hormone. Cox et al. (2010) compared the impacts of swimming and walking on fitness, lipids, body weight, glucose, and insulin in older women and concluded that the type of exercise could impact health benefits.

Martin et al. (1981) presented a simple but sophisticated analytical model for the crawl stroke. The swimmer was modeled as a torso with arms rotating like paddle wheels and they ignored the kick for the sake of simplicity. The model provided insight into various aspects of swimming research, including the relationship between tethered swimming forces and actual propulsive forces during free swimming.

Akis and Orcan (2004) considered a three dimensional analytical framework for crawl stroke swimming where the swimmer was investigated as a body and two arms connected to the body at the shoulder joints. Each arm was considered with three segments. The numerical results achieved from the model were compared with the results of two sets of experiments performed. In the first series of experiments, the tether forces developed in crawl stroke swimming were measured and a linear correlation between the tether force and the stroke rate was obtained. In the second series of experiments, untethered crawl stroke swimming for various arm position angles was recorded. The results were presented in graphical forms and the impact of stroke rate on swimming velocity was discussed.

The primary objective of this paper is to study the effect of two type of swimming exercise on teenagers abilities to participate in sports. The organization of this paper first presents details of our proposed study in section 2 and the results are given in section 3. Finally, concluding remarks are given in the last to summarize the contribution of the paper.

\section{The proposed study}

Swimming is of the most important sports in the world and most countries try to find the most qualified people for participating in world's different championships. Training athletic people in swimming sport is more important in this area of sports compared with other sports. Therefore, in this paper, we perform an empirical investigation to find the effects of various swimming sports on 
swimmers. To reach this objective, the present study investigates the impacts of two different swimming on some teenagers who live in city of Esfahan, Iran. The primary objectives of the proposed study are summarized as follows,

1. We study the effect of interval swimming exercise on the performance of teenagers.

2. We investigate the impact of combined swimming exercise on the performance of teenagers.

3. We compare the performance of these two kinds of exercise on people's performance.

The focus of this study is to compare the performance of two methods before and after two methods of interval and combined breast stroke swimming. The population of this survey includes all teenagers aged 13 and 14 who had, at least, one year of swimming experience. The sampling includes 30 people who were randomly selected and they were divided into two groups of 15 people. One group participated in interval training for three sessions per week and in an eight-week period. Interval training includes speed swimming with $80 \%$ power and interruption with 2 to 3 times as much as exercise time. The second group took part in combined training for three sessions per week and in an eight-week period. At the end of training program, using t-student, we have compared the results. Combined swimming includes different types of exercises .

\section{The results}

In this section, we present details of our survey based on some pairwise t-student tests. Table 1 shows details of our findings,

Table 1

The results of t-student test

\begin{tabular}{lcccccc}
\hline Variable & Test & $\mathrm{N}$ & $\mathrm{M}$ & Standard deviation & t-student & P-Value \\
\hline Interval & Pre-test & 15 & 119.5 & 22.42 & 8.2 & 0.000 \\
Training & Post-test & 15 & 101.14 & 16.18 & & \\
\hline Combined & Pre-test & 15 & 119.5 & 15.24 & 3.5 & 0.001 \\
Training & Post-rest & 15 & 107.5 & 12.34 & & \\
\hline Two & Interval & 15 & 101.5 & 18.6 & 2.01 & 0.12 \\
Groups & Combined & 15 & 107.7 & 12.34 & & \\
\hline
\end{tabular}

In terms of Interval training, the results of Table 1 shows there is a meaningful difference before and after training program was held among teenagers who participated in interval training program when the level of significance is either five or even one percent. In addition, there is also a meaningful difference before and after training program was held among teenagers who took part in combined training program when the level of significance is either five or even one percent. However, the result of pairwise t-test does not indicate any significance between two methods. In other words, two methods could both contribute to teenagers' athletic capabilities but they do not statistically represent different impact.

\section{Conclusion}

We have performed an empirical investigation to find the effects of various swimming sports on swimmers. The focus of this study was to compare the performance of two methods before and after two methods of interval and combined breast stroke swimming. The population of this survey includes all teenagers aged 13 and 14 who had, at least, one year of swimming experience. The sampling includes 30 people who were randomly selected and they were divided into two groups of 15 people. One group participated in interval training for three sessions per week and in an eight- 
week period. The second group took part in combined training for three sessions per week and in an eight-week period. At the end of training program, using t-student, we have compared the results. Combined swimming included various kinds of exercises. The results showed that although there was a meaningful difference before and after two kinds of training programs but there was no different between the performances of these two tests.

\section{Acknowledgment}

The authors would like to thank the officials of general community center of city of Esfahan for their cooperation in this test.

\section{References}

Akis, T., \& Orcan, Y. (2004). Experimental and analytical investigation of the mechanics of crawl stroke swimming. Mechanics Research Communications, 31(2), 243-261

Aspenes, S., Kjendlie, P., Hoff, J., \& Helgerud, J. (2009). Combined strength and endurance training in competitive swimmers. Journal of Sports Science and Medicine 8, 357-365.

Barros, C.P. (2003). Incentive Regulation and Efficiency in Sport Organisational Training Activities. Sport Management Review, 6(1), 33-52

Cox, K.L., Burke, V., Beilin, L.J., \& Puddey, I.B. (2010). A comparison of the effects of swimming and walking on body weight, fat distribution, lipids, glucose, and insulin in older women - the Sedentary Women Exercise Adherence Trial 2. Metabolism, 59(11), 1562-1573.

Coppes, R.P., Smit, J., Benthem, L., Van der Leest, J., \& Zaagsma, J. (1995). Co-released adrenaline markedly facilitates noradrenaline overflow through prejunctional $\beta 2$-adrenoceptors during swimming exercise. European Journal of Pharmacology, 274(1-3). 33-40

Garcia-Marquez, C., \& Armario, A. (1987). Chronic stress depresses exploratory activity and behavioral performance in the forced swimming test without altering ACTH response to a novel acute stressor. Physiology \& Behavior, 40(1), 33-38

Liu, X., Yang, L.J., Fan, S.J., Jiang, H., \& Pan, F. (2010). Swimming exercise effects on the expression of HSP70 and iNOS in hippocampus and prefrontal cortex in combined stress. Neuroscience Letters, 476(2), 99-103.

Kaydos-Daniels, S.C., Beach, M.J., Shwe, T., Magri, J., \& Bixler, D. (2008). Health effects associated with indoor swimming pools: A suspected toxic chloramine exposure. Public Health, 122(2), 195-200.

Martin, R.B., Yeater, R.A., \& White, M.K. (1981). A simple analytical model for the crawl stroke. Journal of Biomechanics, 14(8), 539-548.

Musacchio, N.S., \& Forcier, M. (2008). Adolescent Health. International Encyclopedia of Public Health, 33-48

Salmon, P. (2001). Effects of physical exercise on anxiety, depression, and sensitivity to stress: A unifying theory. Clinical Psychology Review, 21(1), 33-61

Schultz, A., Mendonca, L.S., Aguila, M.B., \& Mandarim-de-Lacerda, C.A. (2012). Swimming training beneficial effects in a mice model of nonalcoholic fatty liver disease. Experimental and Toxicologic Pathology, 64(4), 273-282.

Schoefer, Y., Zutavern, A., Brockow, I., Schäfer, T., Krämer, U. Schaaf, B., Herbarth, O., von Berg, A., Wichmann, H.E., \& Heinrich, J. (2008). Health risks of early swimming pool attendance. International Journal of Hygiene and Environmental Health, 211(3-4), 367-373. 
Wuerth, S., Lee, M.J., \& Alfermann, D. (2004). Parental involvement and athletes' career in youth sport. Psychology of Sport and Exercise, 5(1), 21-33

Zhao, Y., Liu, L.J., Wang, C., \& Li, S.X. (2012). Swimming exercise may not alleviate the depressive-like behaviors and circadian alterations of neuroendocrine induced by chronic unpredictable mild stress in rats. Neurology, Psychiatry and Brain Research, 18(4), 202-207 